Petit-Laurent Charpentier, Claudio Andrés.

Docente investigador Universidad Católica de Temuco, Facultad de Artes y Humanidades.

\title{
Entre lo local y lo global: símbolos de la tradición cultural en los procesos de creación para el turismo.
}

\section{Between the local and the global: symbols of cultural tradition in the processes of creation for tourism.}

\author{
TIPO DE TRABAJO: \\ Comunicación. \\ PALABRAS CLAVE: \\ Identidad Cultural; Símbolos; Turismo; Tradición; Modernidad.
}

KEY WORDS:

Cultural identity; Symbols; Tourism; Tradition; Modernity.

\section{RESUMEN.}

La siguiente comunicación aborda la investigación doctoral acerca de los procesos de creación de productos culturales artesanales que se fundan en la identidad cultural tradicional del Archipiélago de Chiloé y que se conciben para la industria del turismo.

El Archipiélago de Chiloé (Chile) es un lugar que tiene la particularidad de mantener un marcado carácter tradicional en su cultura, y que se ve enfrentado en la actualidad al conflicto con la globalización, en la que el turismo ha jugado un rol muy importante. Por ello desarrollaremos en una primera parte los conceptos que estructuran el análisis: identidad cultural, tradición, turismo y posmodernidad enfocándonos en proporcionar los antecedentes acerca de la realidad cultural de nuestro campo de estudio. Tras exponer esos antecedentes, se explicitará el marco metodológico que ha encauzado la investigación sobre la base de un modelo etnográfico que, a partir de la observación, el registro fotográfico y entrevistas, permitirá el análisis de los objetos artesanales y su carácter mediatizador de significados culturales tradicionales para el contexto del turismo.

En una primera instancia nos abocaremos al diagnóstico del mercado de los productos de diseño artesanal que se ofrecen en Chiloé, analizándolos tanto desde una perspectiva semiótica, como desde el estructuralismo. De ello podremos evidenciar el choque o conflicto que se produce en el contexto del turismo y su impacto en los procesos de creación, generando productos ambiguos, híbridos, que se construyen desde la lógica del mercado intentando reivindicar una identidad cultural tradicional, a veces de manera inadecuada.

Finalmente nos referiremos a un caso de producto de diseño de "modernidad apropiada", concepto desarrollado por Sergio Mansilla, importante investigador sobre Chiloé, y que a modo de conclusión permitirá comprender el rol del diseño en el encuentro y diálogo entre lo local y lo global.

ABSTRACT.

The following communication addresses the doctoral research on the processes of creation of artisan cultural products that are based on the traditional cultural identity of the Archipelago of Chiloé and are conceived for the tourism industry. 


\author{
Petit-Laurent Charpentier Claudio Andrés \\ Entre lo local y lo global: símbolos de la tradición cultural en los procesos de creación para el turismo \\ III CONGRESO INTERNACIONAL DE INVESTIGACIÓN EN ARTES VISUALES :: ANIAV 2017 :: GLOCAL [codificar, mediar, transformar, vivir] \\ http://dx.doi.org/10.4995/ANIAV.2017.5374
}

The Chiloé Archipelago (Chile) is a place that has the peculiarity of maintaining a marked traditional character in its culture, and which is currently facing the conflict with globalization, in which tourism has played a very important role. Therefore, we will develop in a first part the concepts that structure the analysis: cultural identity, tradition, tourism and postmodernity, focusing on providing the background about the cultural reality of our field of study. After exposing these antecedents, the methodological framework that has guided the investigation will be explained on the basis of an ethnographic model that, from the observation, the photographic registry and interviews, will allow the analysis of the artisan objects and their mediating character of cultural meanings the context of tourism.

In the first instance, we will focus on the market diagnosis of the artisanal design products offered in Chiloé, analyzing them both from a semiotic perspective and from structuralism. From this we can highlight the clash or conflict that occurs in the context of tourism and its impact on the creation processes, generating ambiguous, hybrid products that are built from the logic of the market trying to claim a traditional cultural identity, sometimes in a way Inadequate.

Finally we will refer to a product case of design of "appropriate modernity", a concept developed by Sergio Mansilla, an important researcher on Chiloé, and that by way of conclusion will allow to understand the role of the design in the encounter and dialogue between the local and the global culture.

\title{
CONTENIDO.
}

Introducción: Identidad cultural chilota en la modernidad.

Podemos considerar que los dos ejes centrales en los que se sustenta el cambio en las formas de vida en la modernidad son, por un lado, los procesos de mercantilización de la economía dando paso a la sociedad de consumo, y la mediatización de las relaciones humanas. Ambos están relacionados y se derivan de la industrialización y tienen un efecto determinante en la forma de entender el mundo moderno y su devenir posmoderno. (Lipovetsky, 2007; Friedman, 2001; Baudrillard, 1985; Vattimo, 1985, 1994; Habermas, 1985)

La trasformación que significó la industrialización en los procesos productivos, de transporte y comunicación, impactó en la relación del ser humano con su entorno y con los demás. El progreso que prometía la industria, y que auguraba felicidad, pronto se convirtió en un impulso sin sentido en el que la simple novedad se impone como valor primordial decantando en el "agotamiento del impulso modernista hacia el futuro, desencanto y monotonía de lo nuevo, cansancio de una sociedad que consiguió neutralizar en la apatía aquello en que se funda: el cambio" ${ }^{1}$

El auge del consumo y de los medios masivos ha diluido los límites entre la realidad y la simulación que alcanza su estado de refinamiento en el turismo. El viaje se convierte en una búsqueda, un estado de no pertenencia, de trashumancia y de fluctuación, imagen de la incertidumbre en la que el desorientado hombre posmoderno, sin perspectiva de futuro, mira al pasado con nostalgia "como si, por alguna razón, hoy fuésemos incapaces de concentrarnos en nuestro propio presente, como si nos hubiésemos vuelto incapaces de conseguir representaciones estéticas de nuestra propia experiencia actual" ${ }^{2}$.

Es MacCannel (2003) quien alude a la nostalgia como motivación del turismo, planteando que el hombre moderno ha perdido los vínculos con sus espacios cotidianos, con lo propio, cargándolo de connotaciones negativas debido a ese sistema social y cultural tan mediatizado que describíamos antes, y es por ello que desarrolla un interés por la vida de los otros. El mensaje es que lo cotidiano está fuera de lo valioso; que vivimos en él suspendidos y desvinculados de lo real, de la auténtica cultura.

Cuando todo queda obsoleto en poco tiempo, valoramos especialmente lo que ha sido hecho bajo la lógica de la perdurabilidad. Por ello las tradiciones que permanecen aún como vestigio de lo auténtico, son constantemente visitadas. Sin embargo, esa autenticidad no es más auténtica que una simulación verosímil fabricada en gran medida por el mercado. Como plantea Lipovetsky (2007): "Las ciudades históricas se convierten en poblados temáticos para responder a las necesidades de 'autenticidad' de los turistas ávidos de cosa extranjera, de ambiente local y exotismos folclóricos" ${ }^{3}$ Bajo la lógica posmoderna la autenticidad no es más que una imagen que recubre la ruina y la convierte en atracción y ante todo debe corresponder a lo que esperamos de ella.

Según MacCannell (2003) lo que visitaríamos en realidad sería lo que él denomina una producción cultural que se articula a partir de la relación mediatizada entre un modelo cultural y su influencia. El modelo cultural consiste precisamente en aquello que, de entre todas

\footnotetext{
${ }^{1}$ Lipovetsky, Gilles: La felicidad paradójica. Anagrama. Barcelona. 2007. p.9

2 Jameson, Fredric: Teoría de la Posmodernid@d. Editorial Trotta. Madrid. 1996. p.170

${ }^{3}$ Lipovetsky, Gilles: La felicidad paradójica. Anagrama. Barcelona. 2007, p.57
} 
las cosas que forman parte de la cultura, es elevado como un ideal. Y la influencia, en tanto, se entiende como "la creencia o sensación alterada, creada, intensificada que se basa en el modelo" ${ }^{4}$. Eso es lo que ha hecho la industria del turismo en Chiloé las últimas décadas, mediatizado aquel carácter premoderno, esa identidad cultural, para ofrecerla en un mercado ávido de recuperar lo auténtico.

A diferencia de MacCannel, John Urry (1996), plantea que la motivación del viajero, más que en la nostalgia, está en la evasión de la realidad cotidiana. Evasión que se percibe como una pausa en la cual se pretende, más que conectar con otras formas de vida, disfrutar de los placeres de no hacer nada, del descanso del cuerpo o de la diversión que permitirá olvidar los sufrimientos y pesares. El post-turista, como llama John Urry ${ }^{5}(1996)$ al turista posmoderno, es consciente de que lo que va a encontrar en su destino no es más que una especia de montaje teatral, un juego en el que decide participar para poder así desprenderse un instante del peso de la realidad.

\section{Desarrollo: Diseño de Objetos para el turismo en Chiloé.}

El trabajo de campo de la investigación se realizó sobre la base de un modelo de tipo etnográfico, utilizando como técnicas de recogida de información, la observación participante, el registro fotográfico, la entrevista personal, complementado con la revisión documental de literatura relacionada con la cultura chilota tanto tradicional como actual.

El devenir histórico del archipiélago de Chiloé ha dado lugar un sincretismo cultural entre los distintos pueblos que han dominado el territorio: los Chonos, los Veliche, los españoles, los chilenos. Debido a las circunstancias impuestas por el entorno natural inhóspito, aislado y frío, forzó a que las relaciones se sustentaran sobre la idea de la colaboración como mecanismo de subsistencia, lo que significó que "La identidad cultural chilota se construyó básicamente a partir de la práctica del intercambio de bienes y servicios en el marco de un modo de producción orientado, casi siempre, a la satisfacción de necesidades endógenas de sobrevivencia” ${ }^{6}$

Lo que plantea Mansilla (2007) es que el carácter de la identidad chilota está en las relaciones de colaboración y en la relación armónica con el entorno natural y que ello ha determinado los productos culturales. Cuando la industria, el sistema económico neoliberal y la globalización confrontan esa forma de vida, surge la necesidad de protegerla, y emerge la conciencia de la identidad.

El turismo es un factor del neoliberalismo que ha tenido un importante papel en la mutación de la cultura chilota, y su efecto sobre los elementos distintivos de Chiloé ha sido su reducción a fachadas que ocultan las ruinas de un Chiloé ya desaparecido. Sin embargo, a pesar de ello, siguen siendo marcas identitarias eficaces para la distinción de la cultura chilota en el contexto chileno e internacional. Ahora bien, el riesgo está en que el modelo cultural impuesto por el mercado, despoje de aquel real sentido a las producciones culturales, el "sentido humano", que reflejan "los modos de ser y existir de 'los antiguos' a partir de y con los objetos suyos y nuestros" ${ }^{\prime 7}$ Lo relevante está en las significaciones, es decir, en lo que los objetos son capaces de trasmitir respecto a las formas de vivir de los antepasados, de sus formas de ver y concebir el mundo y de relacionarse con él; las formas en que construyeron el orden y los valores que rigieron su convivencia en sociedad.

El proceso cultural que vive Chiloé en la modernidad, consiste en realidad en dos procesos imbricados, uno que va por la superficie y que es el proceso de la cultura global que inunda todo y lo orienta hacia la mercantilización, cancelando todo efecto crítico sobre las relaciones de dominación capitalista; y el otro más profundo, es el proceso que vive la cultura local en reacción ante esa ola enorme que intenta inundarla y sumergirla en el olvido. A partir de ese proceso surge una intelectualidad chilota que busca mantener viva una cultura que se distingue, basándose en "La certeza de que es posible construir una forma de identidad que, aprovechando las posibilidades del mercado y las de la globalización, potencie lo local y lo vuelva una 'avanzada del progreso' desde dentro hacia afuera" $^{8}$

Paradójicamente, aunque el turismo devenga en una escenificación, igualmente funciona como escenario para mantener vivos algunos símbolos que de otro modo habrían desaparecido. La forma concreta de hacerlo son los souvenir, que, en una lógica de mediatización, vehiculizan significados relativos a la identidad cultural de diversas maneras. En una primera instancia, podría decirse que existen dos tipos de souvenir; por un lado, los de origen industrial, propio de lo moderno y por otro los que surgen de procesos de creación artesanales propios de lo tradicional. (Ver ilustraciones 1 y 2)

\footnotetext{
${ }^{4}$ MacCannell, Dean: El turista. Una nueva teoría de la clase ociosa. Editorial Melusina. Barcelona. 2003.

${ }^{5}$ Urry, John: The tourist gaze. Leisure and travel contemporary societies. Sage Publications Ltd. London. 1996

${ }^{6}$ Mansilla, Sergio: "Hay un Dios que todo lo compra: Identidad y memoria de Chiloé en el siglo XXI". Revista Austral de Ciencias Sociales. 2007 № $12,145-158$. P. 151

${ }^{7}$ Mansilla, Sergio: "Chiloé y los dilemas de su identidad cultural ante el modelo neoliberal chileno: la visión de artistas e intelectuales". Alpha, 2006. № 23, 9-36. p. 16

${ }^{8}$ Op. cit. p.35
} 


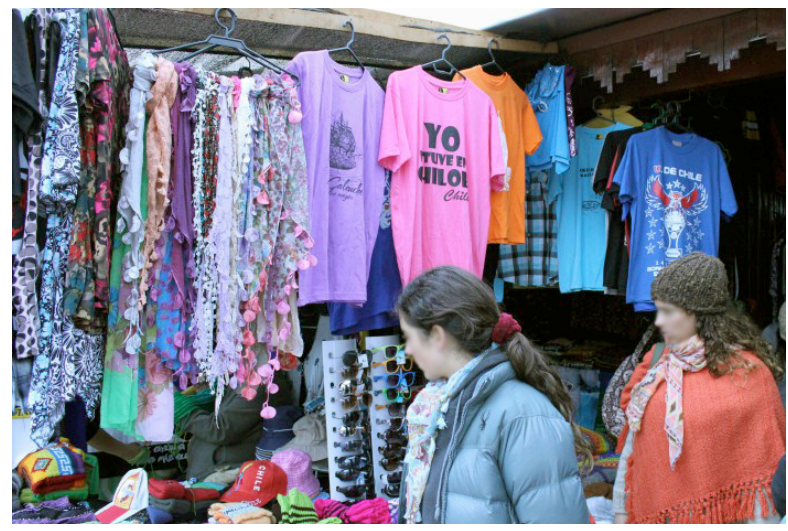

Ilustración 1

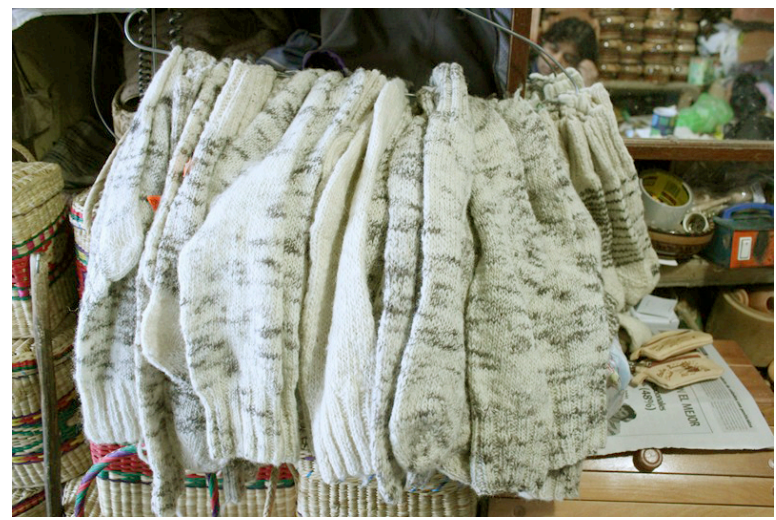

\section{Ilustración 2}

Sin embargo, esa clasificación resulta reduccionista en relación a la complejidad cultural que se produce en Chiloé. Ello se evidencia por ejemplo, en algunos objetos de lana, cuyo sentido se encuentra en las condiciones climáticas caracterizadas por las bajas temperaturas y la lluvia constante propias del archipiélago, lo que sumado a la situación de aislamiento generó la necesidad de elaborar gran parte de los objetos cotidianos a partir de las materias primas que se encontraban a disposición en el entorno natural, por ello la lana ocupó un lugar fundamental en la fabricación de la vestimenta tradicional del chilote, incluido los abrigos, chaquetas, pantalones, vestidos y calcetines que solían usarse sobre el pantalón. Hoy esos elementos constituyen objetos de souvenir. (Ver ilustraciones 3 y 4 )

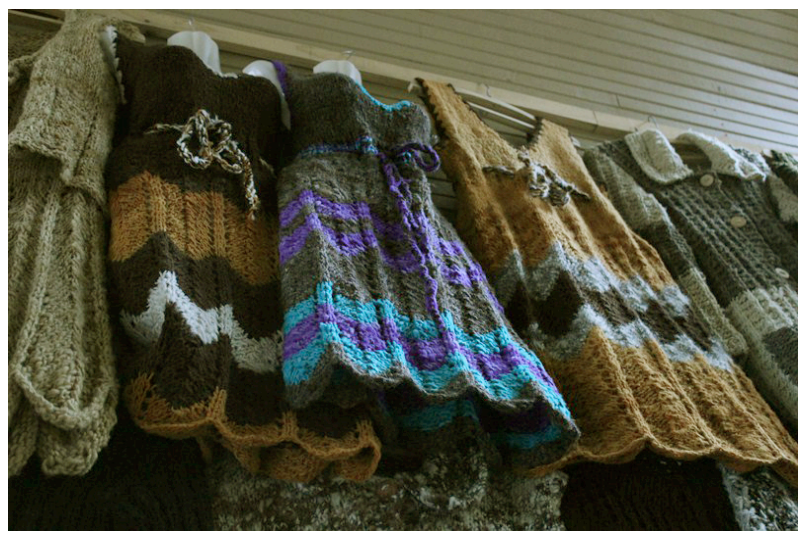

Ilustración 3 


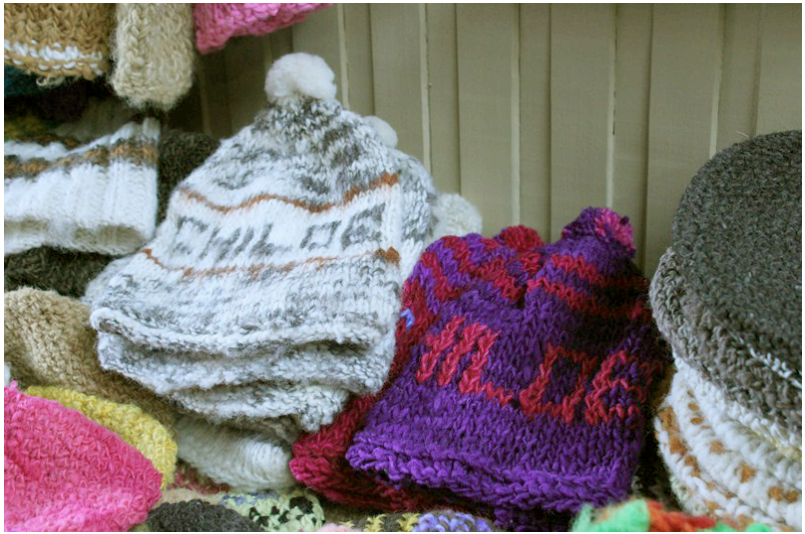

\section{Ilustración 4}

Sin embargo en algunos casos las prendas de lana han sido reducidas al significado más general: objeto de lana, pasando por alto significados derivados del origen y proceso de elaboración. La mediatización por lo tanto implica que el objeto es despojado de atributos significativos que sintetizan el símbolo hasta el límite de dejarlo en muchos casos, vacío, y siendo objetos incoherentes e inadecuados. (Ver ilustración 5). Como plantea Baudrillard: “el mensaje que los objetos trasmiten por su mediación ya está simplificado en extremo y es siempre el mismo: su valor de intercambio. Así, en el fondo el mensaje ya no existe; es el medio el que se impone en su pura circulación" ${ }^{9}$.

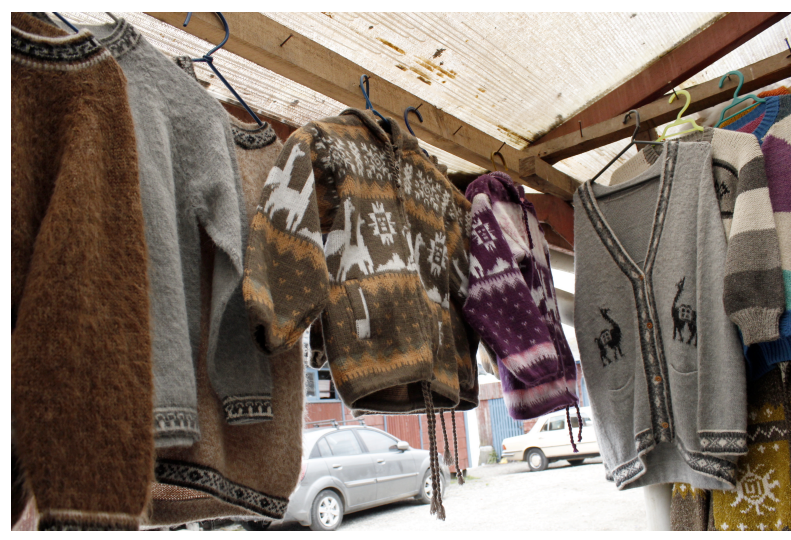

\section{llustración 5}

Otro tipo de objetos en que se ve la hibridez entre elementos culturales modernos y tradicionales son los objetos decorativos de madera. Siendo un material determinante en la cultura chilota, utilizada en la construcción de casas (palafitos), iglesias, embarcaciones y utensilios agrícolas y domésticos, muchos objetos de madera son ofrecidos a los turistas, reproduciendo en miniatura esos elementos culturales. La factura técnica de estos objetos es variada, algunos con un carácter más artesanal que otros, y también con diferentes niveles de connotación de simbolismos culturales. En el caso de las reproducciones en miniatura de las construcciones arquitectónicas características de Chiloé como son los palafitos y las Iglesias patrimoniales, son interesantes algunos casos en que la reproducción respeta ciertos rasgos significativos para remitir a aspectos particulares de esas construcciones, aunque la mayoría sintetiza también al concepto general. (Ver ilustraciones 6 y 7 )

\footnotetext{
${ }^{9}$ Baudrillard, Jean: "El Éxtasis de la comunicación”. La posmodernidad. Kairos, Barcelona, 1985, p.194
} 


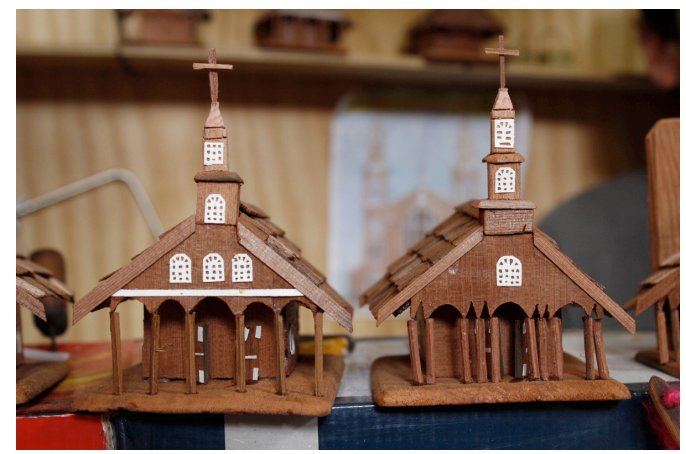

Ilustración 6

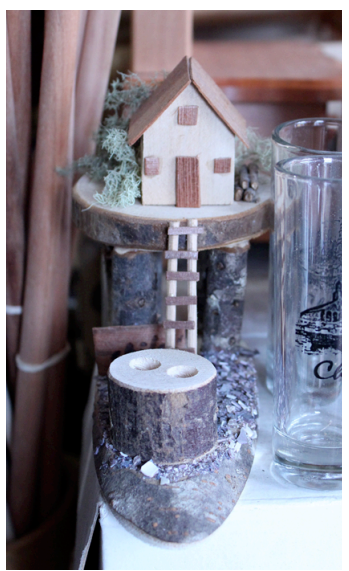

\section{Ilustración 7}

También se utiliza la madera como soporte de imágenes, dibujadas con la técnica del pirograbado, en que se representan desde elementos de la tradición oral chilota, hasta elementos culturales modernos. En estos objetos, la gráfica como lenguaje también trasmite la influencia de la modernidad presente por ejemplo en el estilo tipo comic de algunos retablos. (ver ilustraciones 8 y 9 ) En estos casos los niveles de significación también son reducidos a connotaciones de primer nivel, es decir, pretendiendo trasmitir la idea de rusticidad con el simple hecho de ser de madera.

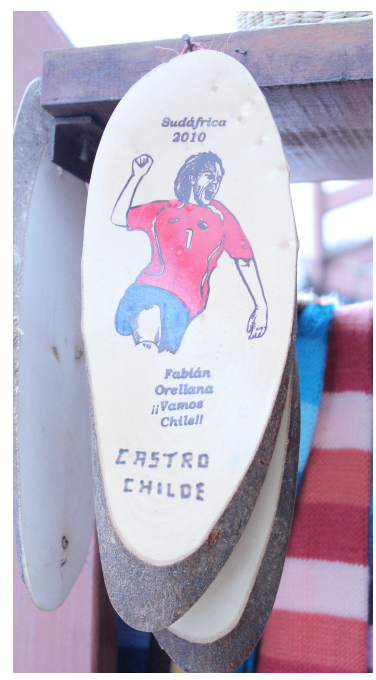

llustración 8 


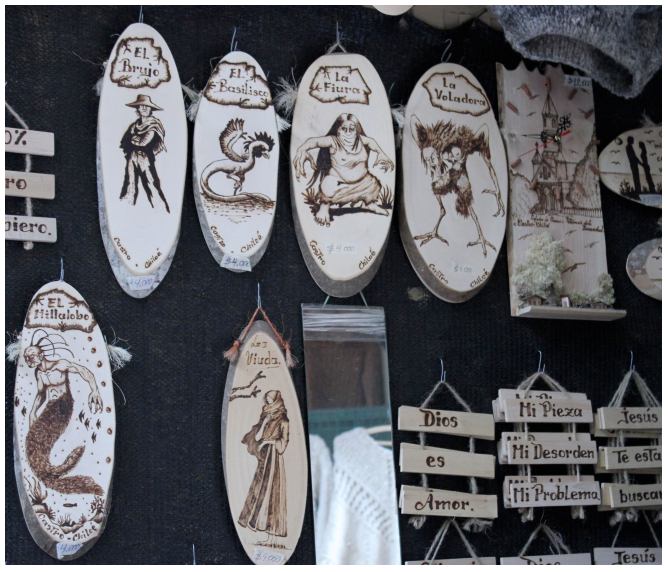

Ilustración 9

Por otra parte, la cestería, utilizada originalmente para elaborar contenedores de alimentos como mariscos y patatas, y también los implementos para tejer, hoy en día el mercado de objetos turísticos oferta este tipo de elementos, tanto a escala normal para su uso práctico, como miniaturizado para su representación simbólica. (Ver ilustraciones 10 y 11)

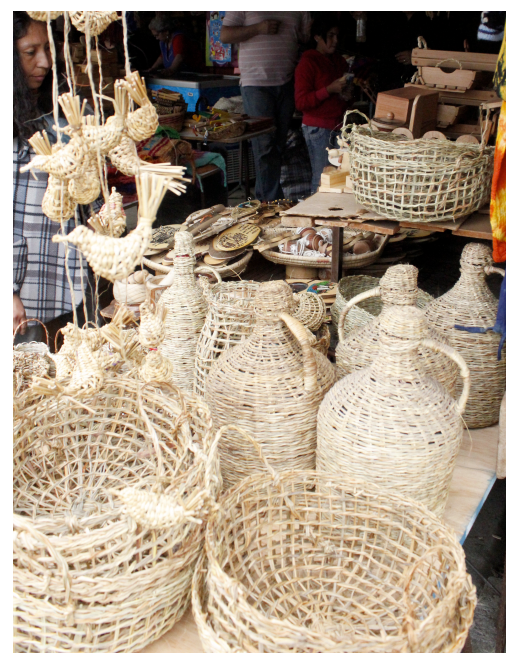

Ilustración 10

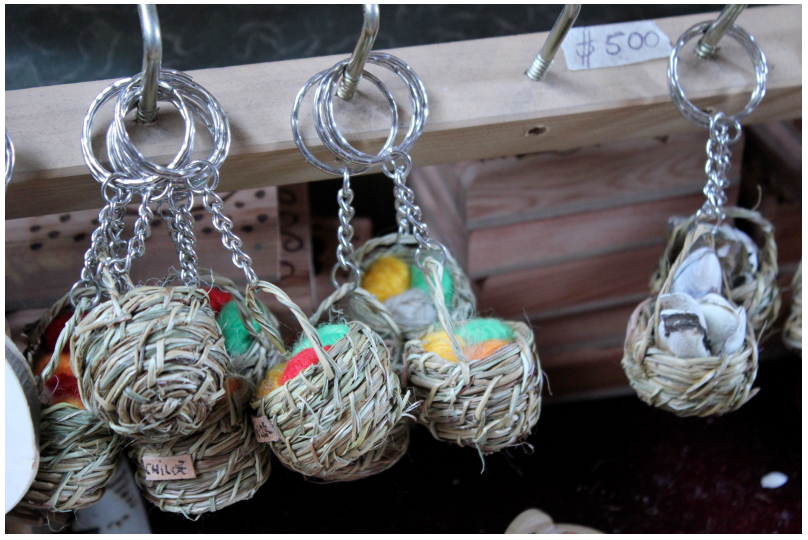

Ilustración 11 
Por lo general la miniaturización es el mecanismo más común para el diseño de souvenir. Reducir proporcionalmente monumentos y objetos y otorgarle una utilidad accesoria, como por ejemplo de llavero o de imán de nevera es la forma en que el objeto se hace portable. En el caso de los objetos de Chiloé, vemos que, a pesar de su reducción, el objeto mantiene bastantes rasgos de autenticidad debido a su producción artesanal, y a que alude a la función original, presentándose con pequeños ovillos de lana, o con conchitas de mariscos.

Otro objeto que tiene un carácter simbólico importante en Chiloé es la muñeca de lana. Además de los utensilios y herramientas, los materiales propios de la isla eran utilizados para confeccionar juguetes, destacando en particular la muñeca de lana tejida. A mediados del siglo XX, se comenzó a utilizar químicos para el teñido de la lana que tradicionalmente era hecho con elementos naturales, haciéndolos más llamativos para los niños que aún jugaban con ellas. Hoy en día estos objetos perviven en el contexto de la industria turística, teniendo una función eminentemente simbólica, ya que pocos niños juegan hoy con ellas.

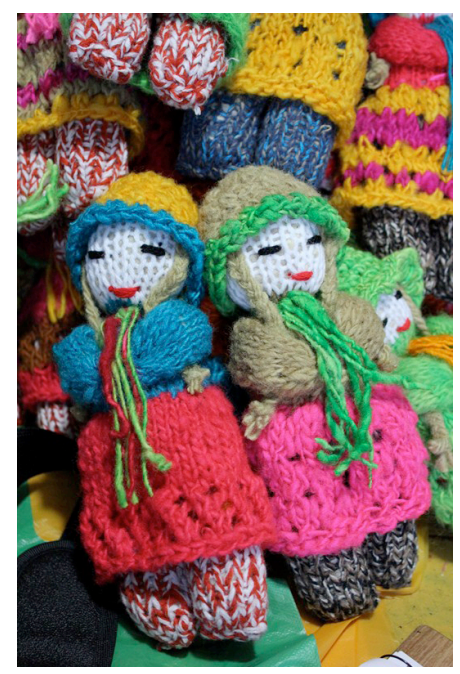

Ilustración 14

Hemos podido evidenciar en el trabajo de campo que el impacto de la modernidad y el turismo, ha significado que algunos objetos tradicionales han reorientado su función hacia lo simbólico, y adquiriendo un nuevo sentido en la realidad cultural actual, lo que en gran parte de los casos ha significado una síntesis que ha degradado las significaciones culturales originales. En palabras de Getino "Al pasar a segundo plano- o directamente a desaparecer- las texturas y los claroscuros que forman parte de la identidad de los pueblos y de los individuos, se jerarquiza en la oferta y la demanda la imagen de los arquetipos. La estandarización de lo simbólico se antepone así a la comprensión y reconocimiento de lo diverso, que es la base de toda cultura y toda comunicación democrática” ${ }^{10}$.

Todo este análisis que se hace en concreto de la realidad actual de la cultura de Chiloé, remite al análisis de la cultura de masas que desarrolla Umberto Eco en "Apocalípticos e integrados" y que se puede sintetizar en la siguiente cita:

"El problema de la cultura de masas es en realidad el siguiente: en la actualidad es maniobrada por 'grupos económicos', que persiguen fines de lucro, y realizada por 'ejecutores especializados' en suministrar lo que se estima de mejor salida, sin que tenga lugar una intervención masiva de los hombres de cultura en la producción. La postura de los hombres de cultura es precisamente la de protesta y reserva. Y no cabe decir que la intervención de un hombre de cultura en la producción de la cultura se resolvería en un noble e infortunado gesto sofocado muy pronto por las leyes inexorables del mercado" ${ }^{11}$

Ahora bien, entendiendo la lógica del contexto cultural actual, y desde la perspectiva que planteara Sergio Mansilla (2006) respecto a asimilar la modernidad desde la memoria, que recoge y genera una cultura "apropiada" entendiendo este concepto tanto como adecuada, como también hecha propia, encontramos objetos que reflejan esa capacidad de adaptación del pueblo chilote. Es el caso de la empresa de artesanía Ñankú. (Ver ilustraciones 15 y 16)

\footnotetext{
${ }^{10}$ Getino, Octavio: Turismo. Entre el ocio y el neg-ocio. Identidad cultural y el desarrollo económico en América Latina y el Mercosur. Ediciones La Crujía, Buenos Aires, 2002, p. 66-67

${ }^{11}$ Eco, Umberto: Apocalípticos e integrados. Fábula Tusquets Editores Barcelona, 2006, p. 59-60
} 


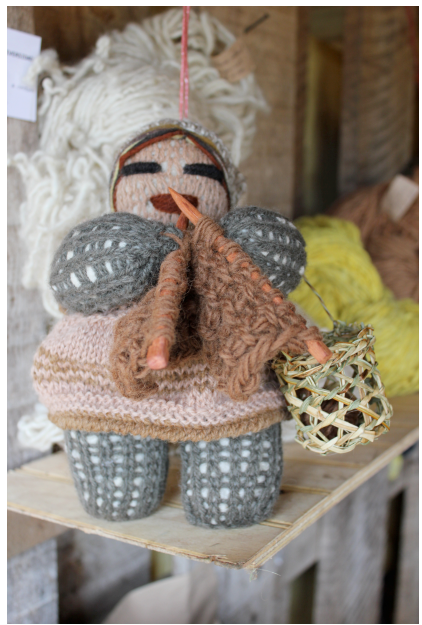

Ilustración 15

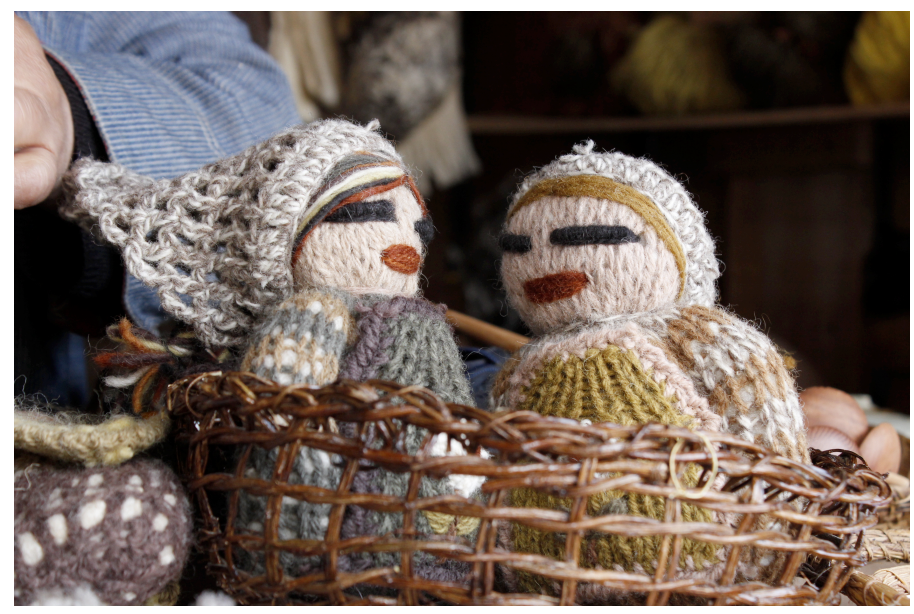

Ilustración 16

Sobre la base de un proceso productivo inspirado en la modernidad industrial, como es la producción por piezas, esta empresa se organiza con diferentes artesanas y artesanos que se especializan cada uno en una parte del proceso de producción, respetando un lineamiento de diseño, desde el teñido de la lana, hasta los detalles. Ese diseño responde por su parte a una reflexión respecto a aspectos identitarios de Chiloé, por ejemplo, el fenotipo del chilote y su vestimenta cotidiana, además de entender la nueva función simbólica del objeto, que ya no es un juguete, por lo que incorpora elementos distintivos de la cultura, como es la cestería o tejidos.

De esta manera, y recogiendo las reflexiones de Sergio Mansilla $(2006,2007,2009)$ resulta ingenuo pensar que la ola de modernidad se detendrá, siendo además absurdo, puesto que ésta ha significado además importantes avances en la calidad de vida. Sin embargo, es necesario que esa modernidad sea asimilada por el chilote desde la memoria, y en ello es importante que los artesanos, que ejercen la labor del diseño de objetos, actúen como hombres de cultura que permitan mantener viva una identidad cultural sustentada en un sentido humano, y no en el vacío del consumismo.

\section{Conclusiones.}

En conclusión, el turismo, industria de lo global por excelencia, se ha articulado como paradigma cultural sobre la paradoja de poner en valor aquello que la misma modernidad y globalización ha destruido: la autenticidad y la identidad cultural, que en Chiloé aún lucha por sobrevivir. Lamentablemente, esa lucha no siempre resulta tan exitosa, pues como hemos visto en este análisis, el mercado muchas veces gana e impone la lógica del arquetipo despojando de profundidad a los significados que el objeto souvenir mediatiza. 
Vemos que en el caso de Chiloé, los objetos reflejan el choque cultural entre la tradición y la modernidad, no sólo ofreciéndose objetos que respondan a una u otra, sino que el mismo objeto manifiesta la ambigüedad y la hibridación de elementos sígnicos de las dos realidades culturales.

Sin embargo, debemos concluir también que la responsabilidad es de la sociedad misma, que permite que el olvido se imponga a la "modernidad de la memoria", y que los procesos de creación queden determinados por principios económicos, de consumo, olvidando que el artesano, como parte de la intelectualidad, juega un rol importante en la preservación de la identidad cultural, enseñando y comunicando al turista, lo que somos, nuestra historia y nuestra forma de ver el mundo en que vivimos.

\section{FUENTES REFERENCIALES.}

Baudrillard, Jean: “El Éxtasis de la comunicación”. La posmodernidad. Kairos. Barcelona, 1985.

Eco, Umberto: Apocalípticos e integrados. Fábula Tusquets Editores, Barcelona, 2006.

Friedman, John: Identidad cultural y proceso global. Amorrortu Editores. Buenos Aires 2001

Getino, Octavio: Turismo. Entre el ocio y el negocio. Identidad cultural y el desarrollo económico en América Latina y el Mercosur. Ediciones La Crujía. Buenos Aires, 2002.

Habermas, Jürgen: "La modernidad, un proyecto incompleto". La posmodernidad. Kairos, Barcelona, 1985

Jameson, Fredric: Teoría de la Posmodernid@d. Editorial Trotta. Madrid. 1996

Lipovetsky, Gilles: La felicidad paradójica. Anagrama. Barcelona. 2007

MacCannell, Dean: El turista. Una nueva teoría de la clase ociosa. Editorial Melusina. Barcelona. 2003.

Mansilla, Sergio: "Chiloé y los dilemas de su identidad cultural ante el modelo neoliberal chileno: la visión de artistas e intelectuales". Alpha. 2006, № 23, 9-36.

Mansilla, Sergio: "Hay un Dios que todo lo compra: Identidad y memoria de Chiloé en el siglo XXI". Revista Austral de Ciencias Sociales, 2007, № 12, 145-158.

Mansilla, Sergio: "Mutaciones culturales de Chiloé: los mitos y las leyendas en la modernidad neoliberal isleña". Convergencias, Revista de Ciencias Sociales, Universidad Autónoma de México, 2009, № 51, 271-299.

Urry, John: The tourist gaze. Leisure and travel contemporary societies. Sage Publications Ltd., London, 1996

Vattimo Gianni: El fin de la modernidad. Editorial Planeta-De Agostini S.A., Barcelona, 1985.

Vattimo, Gianni et al.: En torno a la posmodernidad. Anthropos, Santafé de Bogotá, 1994.

Yáñez, Rodrigo: Una aproximación a las transformaciones identitarias del archipiélago de Chiloé. En VIII Congreso Latinoamericano de Sociología Rural, Porto de Galinhas. 2010. 